\title{
Histomorphological Assessment of Spermatogenesis in African Catfish Clarias gariepinus with reference to Spermatogonial Proliferation
}

\author{
Eme Efioanwan Orlu ${ }^{1}$, Godwin Nwachukwu Isitor ${ }^{2}$ \\ Department of Applied and Environmental Biology, Rivers State University of Science \& Technology \\ P.M.B.5080, Nkpolu,Port Harcourt,Rivers State Nigeria
}

\begin{abstract}
The fresh water catfish is the most predominant species of the teleost bred in captivity in Nigeria and has provided a model for the study of reproduction in aquatic vertebrates, but information on the number of mitotic divisions and spermatogonial generations remains inconclusive. This investigation aimed at assessing the number of generations of spermatogonia produced prior to meiotic division during spermatogenesis. Results indicate that spermatogenesis occurred in cysts and germ cells at the same stage of maturation formed clones round the Sertoli cell. Spermatogonia went through 5 rounds of mitotic divisions to produce 6 generations of $B$ clones $\left(B_{1}-B_{6}\right)$ before producing primary spermatocytes, secondary spermatocytes and haploid spermatids . The process of spermiation was not synchronized in all clones of the cysts. Cellular maturation and spermiation occurred in the most advanced clones. Each cyst appeared to simulate the spermatogenic process that occurs in the seminiferous epithelium of mammalian testis. It is concluded that spermatogenesis in captive bred African catfish Clarias gariepinus is cystic, and that spermatogonia arrangement in the cysts is unrestricted and progresses through 5 mitotic divisions to produce 64 spermatogonia type B, 100 mono-flagellated spermatozoa. Approximately, 68\% germ cells complete spermatogenesis, following $32 \%$ germ cell loss.

Keywords: Catfish, germ cell cyst, spermatogenesis, spermatogonia, testis
\end{abstract}

\section{Introduction}

In silurid fishes and indeed vertebrates, spermatozoa develop from spermatogonial primordial germ cell which first proliferates by a series of mitotic divisions, then differentiates into primary spermatocytes that undergo first meiotic division to produce haploid secondary spermatocytes and an equational division to become round spermatids. The haploid spermatids undergo a maturation process including development of a flagellum into motile spermatozoa endowed with fertilizing capacity. These are released into the lumen of seminiferous tubules during spermiogenesis. Both processes (spermatogenesis and spermiogenesis) are controlled and regulated by the somatic interstitial cells of Leydig that produce gonadal sex steroid hormone .The production of sex hormones by activation of Leydig cells initiates the process of spermatogenesis which is sustained by the Sertoli cells. The Sertoli cells referred to as sustentacular cells provide an environment for differentiation and maturation of the germ cells and separate them from all other cells through the bloodtestis-barrier by forming Sertoli/germ cell complexes in the germinal epithelium [1].

The number of functional spermatozoa produced by each primordial spermatogonium $\mathrm{A}$ is a function of the number of B type spermatogonia committed to undergo meiosis which in turn depends on the number of mitotic divisions that the B type spermatogonium undergoes before differentiation into primary spermatocytes. This number is genetic and species specific [2;3]. Various numbers have been reported in different species, including the guppy fish 14 generations [4] Zebrafish 9 [5], rainbow trout 6 [6] . The resultant primary spermatocytes must undergo two meiotic divisions before differentiation, and maturation into spermatozoa. In fish, spermatogenesis has been reported to occur in cysts $[7 ; 8 ; 9 ; 10 ; 11 ; 12]$ with the proliferating germ cells at the same stage of maturity forming clones surrounded by extensions of the Sertoli cells even as its number per cyst is species specific [13]. The increase in cyst volume has been reported to coincide with rapid mitotic division of the spermatogonia and would cease as occluding junctions begin to appear between neighboring Sertoli cells [ 14]. Germ cell degeneration, accompanied by cellular loss, has been reported during spermatogenesis in fish [13;3] and in domestic fowl Gallus domesticus [15]. The number of spermatids supported per Sertoli cell is a function of the cellular carrying capacity of the Sertoli cell; viz: 100 in Tilapia and guppy [16] 8-10 in rats and mice [17], and approximately 100 in the domestic fowl, Barred Plymouth Rock [18]. 


\section{Materials And Methods}

\subsection{Location of Experiment:}

The experiment was carried out from February to December 2013 in the Department of Applied and Environmental Biology, Rivers State University of Science and Technology, Port Harcourt, Nigeria,[Coordinates :448'14” N 6059'12”E]

2.2. Experimental Fish and management protocol: Fingerlings of Clarias gariepinus were procured from Tonebo Farms and transferred in a fifty litter jerry can with water to the Department of Applied and Environmental Biology. They were reared in three tanks in triplicate and fed with standard ration from February to October 2013.Water temperature was monitored throughout the period of the experiment. All fish used in this investigation were captive-bred in the pond which was drained with a motorized pump and fresh water was introduced daily. The rearing environment was basically disease-free. All experimental procedures were conducted with full compliance with the institutional animal care protocols at the Rivers State University of Science and Technology, by following approved guidelines and ethics for the treatment of experimental animals.

\subsection{Experimental Procedure:}

Thirty adult male (nine months old) fresh water catfish, Clarias gariepinus, selected randomly with mean body weight of $965.88 \pm 15.42 \mathrm{~g}$ were used for this investigation.

\subsection{Data Collection}

Data was collected on body weight, histology of the testes, cytology and quantitative measurements of the germ cells in the cysts of the seminiferous epithelium. Evaluation of the number of primary spermatocytes and spermatids was carried out by counting with ocular graticule.

\subsection{Histology of the testis:}

Fish were weighed and euthanized with ethyl ether, after which they were dissected and the testes removed. Known weights of the samples of the right testis were fixed in Bouin's fixative solution for 24 h.Tissues were washed in $70 \%$ ethanol and thereafter dehydrated in increasing concentrations of ethanol, cleared in three changes of Chloroform and embedded in paraffin. Histological sections of $5 \mathrm{~m} \mu$ thick were floated and flattened in water at $40^{\circ} \mathrm{C}$, then picked with clean slides smeared with Mayer's egg albumin and stained with Hematoxilyn and eosin(H\&E)[18]. Stages of spermatogenesis, cytology and cellular histometry were carried out on 20 randomly selected lobules which were observed at low magnification(X10). Identification of spermatogenic elements and histometric analyses were carried out at X100 oil immersion lens, using a digital Microscope Model DB1-180M . Images were captured, processed, and the cellular diameter was determined with a DN2 software.

\subsection{Identification of Spermatogenic Elements}

Cells repeatedly found together and nursed by the same Sertoli cell at different stages of spermatogenesis were noted and considered as associations.

Spermatogonia were identified by their unique location adjacent to the Tunica albuginea. They appeared to produce new spermatogonial cysts characterized by the distribution of marginal heterochromatin. All cellular morphology was identified according to the combined methods of previous authors $[19 ; 1 ; 5]$.

The primary spermatocytes were identified by their nuclear size, the chromatin spread and by the presence of meiotic metaphase figures. The spermatids were identified by the nuclear diameter, and by their position close to the collecting duct.

\subsection{STATISTICAL ANALYSIS}

All data collected were subjected to paired t-test to assess the difference in the number of germ cells observed in the same clones in different samples using the XLSTAT 2012 package.

\section{Results}

The results of the histometric and histomorphological assessment of the testis of Clarias gariepinus carried out on Hematoxylin -Eosin -stained paraffin sections of the seminiferous epithelium are presented in Fig. 1.(A-U). The cross section of the testis revealed two compartments, the interstitial compartment which occurred between the seminiferous lobules and accommodated the interstitial cells of Leydig, macrophages, blood and lymphatic vessels and fibroblasts, and the tubular compartment represented by germinal seminiferous tubules. The tubular compartment was populated by the spermatogenic cells and Sertoli cells. 
Spermatogenesis occurred in cysts, and the germ cells at the same stage of maturation formed clones around the Sertoli cell. Clones of different germ cell types were observed per cyst: spermatogonia $\operatorname{spgB}\left(\right.$ Fig. $1 \mathrm{~A}$ ), early primary spermatocytes $1^{\circ} \mathrm{spc}$ (Fig.1A), late primary spermatocytes with meiotic figures (MI)(Fig.1A), secondary spermatocytes $\left(2^{\circ} \mathrm{spc}\right)$ and spermatids (R) (Fig.1A.).

The interstitial cells of Leydig were found in clusters of about 8-10 cells with spherical nuclei with respect to cytoplasm/nuclear ratio. The cytoplasm was also quite eosinophilic while the nucleus was ovoid with relatively diffused heterochromatin pattern (Fig. $1 \mathrm{~B}^{*}$ (IC). Also observed was spermatogonia A differentiated (arrow).

\subsection{Spermatogonial generations and Sertoli cell barrier}

A section of the cyst showing A-type spermatogonium undifferentiated (spgA und), Leydig cells (LC) and spermatogonia B undergoing division into a clone ( $\operatorname{spgB}$ ) is shown in Fig.1 ${ }^{* * *}$. Spermatogonia B was observed to systematically proliferate by mitotic division into $\mathrm{B}_{1}$ (Fig.1D) $\mathrm{B}_{2}$ (Fig.1C) $\mathrm{B}_{3}$ (Fig.1E) $\mathrm{B}_{4}$ (Fig.1E) $\mathrm{B}_{5}$ (Fig.1E,F\&G) B $_{6}$ (Fig.1E \&G) clones ( Fig.1C-J). Spermatogonia went through 5 mitotic divisions to produce 6 generations before they became committed to undergo meiotic division as primary spermatocytes. The last mitotic peaks producing $\mathrm{B}_{6}$ cell clones appeared to be crucial as seen by the now very prominent Sertoli cell nuclei (SC) (F1. G\&H), the cytoplasm of the Sertoli cell has expanded to surround the germ cell clones thereby demarcating the basal compartment from the adluminal compartment. This process also resulted in the formation of tight occluding junctions between neighboring Sertoli cells termed the blood -testis barrier (Fig.1G\&H),more spermatogonia B can be seen in Fig.1 (I\&J). B-type spermatogonia that have completed the last mitotic division in the basal compartment are transferred by the expanding Sertoli cell cytoplasm into the adluminal compartment, thereby committing them to undergo meiotic division.

\subsection{Meiotic and Postmeiotic germ cells}

Differentiation into early stage primary spermatocyte $\left(1^{\circ} \mathrm{spc}\right)$ was observed in Fig.1K, also shown are secondary spermatocytes undergoing second meiotic division (MII) as well as early stage spermatids (R).The early primary spermatocytes Leptotene/Zygotene (LZ) are highlighted in Fig.1L. The primary spermatocytes were identified based on their nuclear diameter and the spread of heterochromatin. The Leptotene/Zygotene was characterized by intensely stained chromatin clumped together at the center or towards the periphery of the nucleoplasm. Pachytene spermatocytes were smaller than the zygotene with condensed chromatin visible as tangled threads throughout the nucleoplasm (Fig.1M).Several stages of cellular development were captured in association in this cross section including spermatogonia A, Pachytene primary spermatocytes $(\mathrm{P})$ secondary spermatocytes $\left(2^{\circ}\right)$ and spermatids $(\mathrm{R})$ all in a linear cluster around the Sertoli cell (SC). Diplotene primary spermatocytes are shown in Fig.1N in association with first meiotic metaphase figures (MI), secondary spermatocytes $\left(2^{\circ}\right)$ with second meiotic metaphase figures (MII), spermatids in early maturation and late stages undergoing differentiation and maturation into spermatozoa ( R).Pachytene primary spermatocyte $(\mathrm{P})$ is highlighted in Fig.1 $\mathrm{O}$, while second meiotic metaphase(MII) and maturing spermatids ( $\mathrm{R}$ ) are highlighted in Fig.1P. Diplotene (D), first meiotic metaphase( MI) and matured spermatids $\left(\mathrm{R}_{3}\right)$ are shown in Fig.1Q. The process of spermiation and release of matured spermatozoa into the lumen is shown in Figures $1 \mathrm{~S}-\mathrm{U}$. It is worthy of note here that spermiation did not occur throughout the entire cyst simultaneously, rather, the most mature clones undergo spermiation while the immature one continue in development.
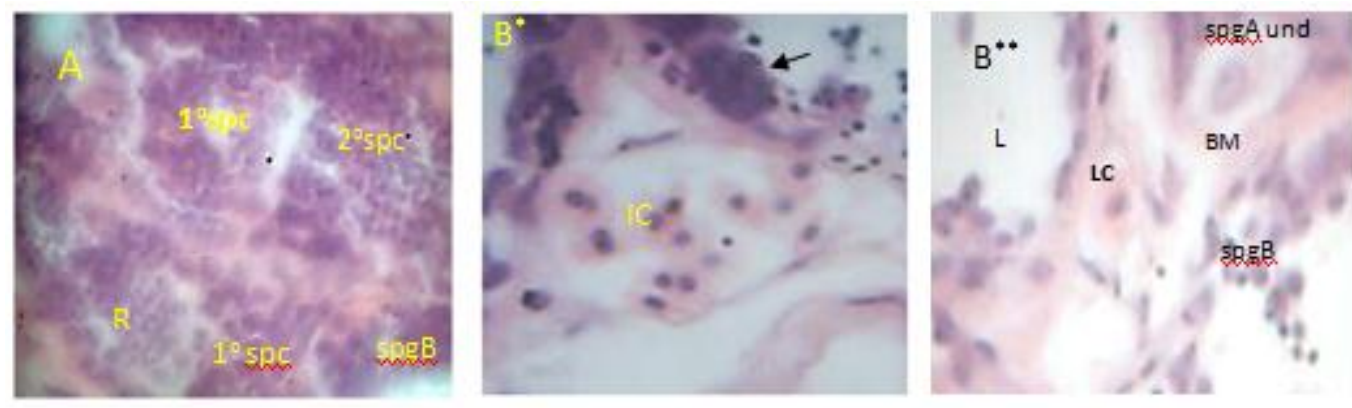

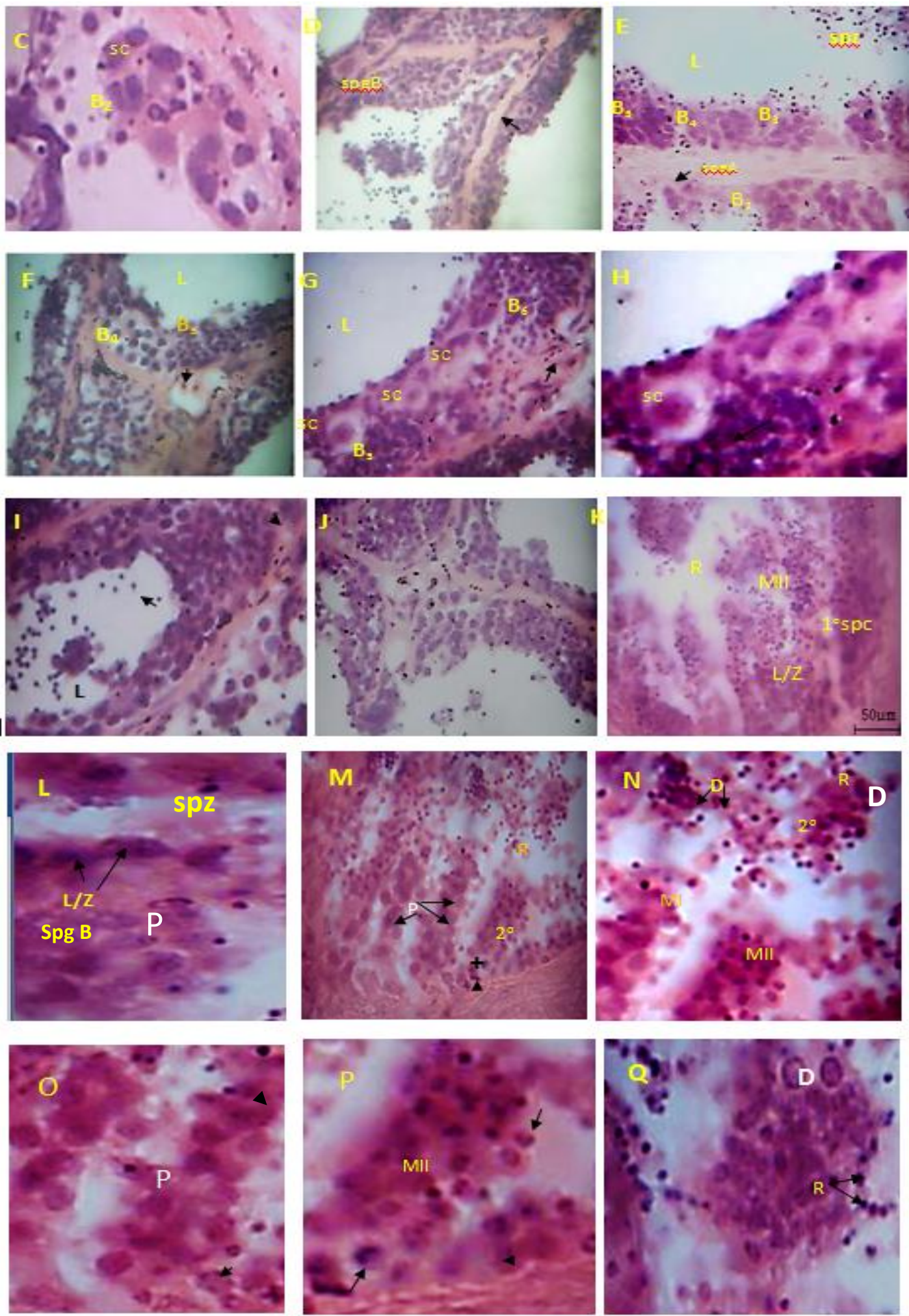



Fig.1Cross section of testis of African catfish during active spermatogenesis

(A) Different germ cell cysts observed during spermatogenesis in African catfish from spermatogonia A (spgA) to spernatogonia B ( $\mathrm{spgB})$ to primary spermatocyte $\left(1^{\circ} \mathrm{spc}\right)$, secondary spermatocytes and spermatids before spermiation. Cluster of interstitial cells of Leydig (IC)( Fig.1 B*) and differentiated spermatogonia A (arrow).Fig.1B ${ }^{* *}$ shows undifferentiated spermatogonium A ( $\operatorname{spg}$ A und),early B(spgB).Clones of early spermatogonia B ( $B_{2}$ clustered around Sertoli cell(SC) (Fig.1C).Early(arrow) and late (spgB) clones of B type spermatogonia (Fig.1D).Four generations of spermatogonia $\mathrm{B}\left(\mathrm{B}_{2}, \mathrm{~B}_{3}, \mathrm{~B}_{4}, \mathrm{~B}_{5}\right)$ lumen without spermatozoa (Fig.1E). Fig.1F shows early and B spermatogonia $\left(3_{3}, B_{4}\right)$, Leydig cell (arrow head).Late spermatogonia $\mathrm{B}\left(\mathrm{B}_{5}, \mathrm{~B}_{6}\right)$, Sertoli cell(sc) cytoplasmic processes expanding to surround the late $\mathrm{B}$ spermatogonia following the last mitotic division and forms tight occluding junctions as blood -testis barrier between neighbouring late stage spermatogonia B clones.More B type spermatogonia are shown in Fig.1 (I\&J). Early primary spermatocytes $\left(1^{\circ} \mathrm{spc}\right)$ at Leptotene/Zygotene (L/Z),secondary spermatocytes undergoing second meiotic division(MII),early round spermatids $(\mathrm{R})($ see Fig.1K).Early primary spermatocytes $(\mathrm{L} / \mathrm{Z})$ are shown in Fig.1 (L).Late primary spermatocytes at Pachytene (P) and secondary spermatocytes $\left(2^{\circ}\right)$ with spermatids (R )an be seen in Fig.1 (M).Fig.1 $\mathbf{N}$ shows late primary spermatocytes at Diplotene(D) undergoing first meiotic division ( MI),secondary spermatocytes $\left(2^{\circ}\right)$ meiotic metaphase figures (MII) and early spermatids(arrow).Pachytene clones shown in Fig.1( O).Fig.1P, has early stage spermatids while $\mathbf{Q} \&, \mathbf{R}$ show late stage spermatids ( $R$ arrow) awaiting spermiation. The process of spermiation cen be observed in Fig.1 S,T,U.

\section{Discussion}

\subsection{Testis structure}

The gross structure of the testis of the African catfish Clarias gariepinus showed paired elongated lobes with the caudal region presenting ostentatious seminal vesicles [11] in contrast to other species [6] .The paraffin processed section stained with H\&E showed a remarkable similarity to the testicular epithelium of vertebrates including other fish species as Tilapia [5], Atlantic cod [19], mammals [17], domestic fowl [18]. The testicular cross section was composed of two compartments, the interstitial compartment and the germinal epithelium. The interstitial compartment contained the Leydig cells identified by their nuclear morphology and by their location, as well as, presence of blood vessels and connective tissues (Fig.1B).The germinal epithelium was demarcated from the interstitial compartment by the basement membrane and was made up of the basal compartment and adluminal compartment, and contained the sustentacular Sertoli cells as well as germ cells at 
various stages of development. This investigation confirmed earlier report [11] that the germinal epithelium of Clarias gariepinus is cystic in nature (Fig.1A) as other reports [1;5]. Spermatogenesis in this species progressed from the spermatogonia type A undifferentiated (spgA und) identified as a single cell not connected to clone members and having large pale ovoid nucleus (Fig.1B ${ }^{* * *}$ ) followed by differentiation into B type .Note the beginning of mitotic proliferation of type B spermatogonium ( $\mathrm{spgB}$ ). Each clone appears to be enclosed by the Sertoli cell cytoplasm, maintained and nurtured through the two meiotic divisions until spermiation.

\subsection{Spermatogonial generations}

The arrangement of the spermatogonia population appeared to be similar to the unrestricted arrangements as spermatogenesis occurred along the entire length of the testis. Spermatogonia arrangement has been described in Gadus morhua [19], tilapia, Oreochromis niloticus [20],Solea senegalensis [21], In Clarias gariepinus a cyst contains several clones of germ cells at different developmental stages, each clone supported by a Sertoli cell, thereby exhibiting the characteristic histological picture of fish testes in Fig.1.The spermatogonia germ cells went through 5 rounds of mitotic proliferation 6 generations of differentiated spermatogonium ( $\mathrm{B}_{1}\left(2\right.$ cells)(Fig,1D), $\mathrm{B}_{2}\left(4\right.$ cells)(Fig.1C), $\mathrm{B}_{3}$ (8 cells)(Fig.1E) , $\mathrm{B}_{4}\left(16\right.$ cells)(Fig.1E \& F), $\mathrm{B}_{5}$ (32 cells ) (Fig.1E \& F), and $\mathrm{B}_{6}(64$ cells )(Fig.1E \& G) identified on the basis of their nuclear heterochromatin distribution which appear as lumps on the nuclear envelop, the number of cells per clone, their characteristic clustering around the Sertoli cell, their location close to the basement membrane in the basal compartment for the early B type and bridge formation of daughter cells due to incomplete cytokinesis observed in the late stage B spermatogonia (Fig.1C-J).The number of generations of proliferating spermatogonia is species specific as it is genetically determined. Various numbers have been reported in different species; 14 generations in the guppy [4] ,6 in the rainbow trout [6], 5 in African catfish [3] ,9 in the zebrafish [5] and 8 in Tilapia [1]. There was a systematic reduction in the germ cell volume with each mitotic division (Fig.1B-J). The A und spermatogonia was observed as the largest germ cell (Fig.1 B) and appeared individually with oval nucleus and one nucleolus, little or no heterochromatin in the nucleus and a relatively large cytoplasmic volume.

\subsection{Meiotic and Postmeiotic germ cells}

Following the last mitotic division the B spermatogonia clones differentiated into meiotic cells at early stage primary spermatocytes (Leptotene/Zygotene) (Fig.1K-L).This process transferred the differentiating cells from the basal compartment to the adluminal compartment by the due expansion of the Sertoli cell cytoplasm to surround the differentiating B spermatogonia clones. Simultaneously, the Sertoli cell also created tight occluding junctions forming the blood- testis barrier between the basal and the adluminal compartment (Fig.1G\&H).The primary spermatocytes were identified with light microscopy based on their nuclear characteristics such as size, diameter, degree of condensation of heterochromatin, as well as, the presence of meiotic metaphase figures associated with Diplotene primary spermatocytes (Fig.1 K-Q). The early stage primary spermatocytes Leptotene (Fig.1K-L) would complete differentiation into Zygotene $\rightarrow$ Pachytene(Fig.1 M) $\rightarrow$ Diplotene (Fig.1N,Q) $\rightarrow$ first meiotic division $(\mathrm{MI})($ Fig. $1 \mathrm{~N}) \rightarrow$ secondary spermatocytes $\left(2^{\circ}\right)$ $($ Fig. $1 \mathrm{M}, \mathrm{N}) \rightarrow$ second meiotic division $(\mathrm{MII})($ Fig.1P,Q) $\rightarrow$ spermatids (R)(Fig.1M,N)and maturation into spermatozoa (Fig.1S,T,U).The leptotene/Zygotene were characterized by intensely stained chromatin clumped together at the center or towards the periphery of the nucleoplasm. Pachytene spermatocytes were smaller than the zygotene with condensed chromatin visible as tangled threads throughout the nucleoplasm (Fig.1M).Several stages of cellular development were captured in association in this cross section including spermatogonia A, Pachytene primary spermatocytes ( P) secondary spermatocytes $\left(2^{\circ}\right)$ and spermatids $(R)$ in a linear cluster around the Sertoli cell, almost like other vertebrate epithelium.This type of association had been reported in the Atlantic halibut Hippoglosus hippoglosus [22].Diplotene primary spermatocytes were observed in association with first meiotic metaphase figures (MI). ).Secondary spermatocytes undergoing equational division known as meiosis II were also sometimes found associated with meiotic metaphase figures(MII) and early round spermatids (R). The round spermatids went through maturation into spermatozoa with spherical nucleus having one flagellum, and showing no evidence of acrosome. These mature spermatozoa were released from the Sertoli cell cytoplasm into the lumen during spermiation (Fig.1S,T,U).This characteristic feature has been described in other teleost species spermatozoa [23; 24,].

\subsection{Sertoli cell efficiency}

Each spermatogonium A, would, theoretically, produce 64 B type spermatogonia to differentiate into primary spermatocytes and undergo two meiotic divisions to produce theoretically 256 spermatids. However, quantitative analysis of the spermatogenic cells revealed cellular loss of approximately $32 \%$ as at the last mitotic division such that fewer spermatogonia were committed to meiosis. During the first meiotic division (MI), another 32\% loss was observed. These cellular losses reduced the actual number of spermatozoa produced by one primordial spermatogonia to approximately 100 . The cellular carrying capacity of the Sertoli 
cell being species specific thus determined the percentage cell loss during spermatogenesis. Cellular maturation and spermiation only occured in the most advanced clone.There was no synchronized spermiation of all clones in the cyst (Fig.1S,T,U). Therefore, it appeared each cyst of the catfish simulated the spermatogenic process that occur in the seminiferous epithelium of the mammalian testis.

It is concluded that spermatogenesis in captive bred African catfish Clarias gariepinus is cystic, that spermatogonia arrangement in the cysts is unrestricted and they go through 5 mitotic divisions to produce 6 generations of differentiated spermatogonia B. After two meiotic divisions of the spermatocytes, approximately 100 round spermatids are produced which mature into mono-flagellated spermatozoa following $32 \%$ germ cell loss during the last mitotic division and at the second meiotic division, indicating that only about $68 \%$ of the germ cells completed spermatogenesis in the fresh water African catfish.

\section{REFERENCES}

[1] Schulz, R.W., L.R. de Franca, J.J. Lareyre, F. Le Gac, H. Chiarini-Garcia, R.H. Nobrega and T. Miura, 2010. Spermatogenesis in fish. Gen. Comp. Endocrinol., 165: 390-411.

[2] Ando,N.,Miura,T.,Nader,M.R.,Miura,C.,Yamauchi,K.,2000.A method for estimating the number of mitotic divisions in fish testes.Fish.Sci.66,299-303.

[3] Schulz RW, Menting S, Bogerd J, Franc, a LR, Vilela DAR, Godinho HP.2005. Sertoli cell proliferation in the adult testis-evidence from two fish species belonging to different orders. Biol Reprod 73:891-898.

[4] Billard,R.,1986.Spermatogenesis and spermatology of some teleost fish species, Reprod. Nutr.Develop.26,877-920.

[5] Leal, M.C., Cardoso, E.R., Nóbrega, R.H., Batlouni, S.R., Bogerd, J., França, L.R., and Schulz, R.W.2009. Histological and Stereological Evaluation of Zebrafish (Danio rerio) Spermatogenesis with an Emphasis on Spermatogonial Generations Biol. Reprod. 81(1):177-187

[6] Loir,M.,1999.Spermatogonia of rainbow trout:II.In vitro study of the influence of pituitary hormones, growth factors and steroids on mitotic activity.Mol. Reprod. Develop.53,434-442.

[7] Loir, M., C. Cauty, P. Planquette and P.Y. Le Bail, 1989. Comparative study of the male reproductive tract in seven families of South-American catfishes. Aquat. Living. Resour., 2: 45-56.

[8] Chaves-Pozo, E., V. Mulero, J. Meseguer and A.G. Ayala, 2005. An overview of cell renewal in the testis throughout the reproductive cycle of a seasonal breeding teleost, the gilthead seabream (Sparus aurata L.). Biol. Reprod., 72: 593-601.

[9] Suwanjarat, J., T. Amornsakun, L. Thongboon and P. Boonyoung, 2005. Seasonal changes of spermatogenesis in the male sand goby Oxyeleotris marmoratus Bleeker, 1852 (Teleostei, Gobiidae). Songklanakarin J. Sci. Technol., 27: $425-436$.

[10] Van Dyk, J.C. and G.M. Pieterse, 2008. A histo-morphological study of the testis of the sharptooth catfish (Clarias gariepinus) as reference for future toxicological assessments. J. Applied Ichthyol., 24: 415-422.

[11] Orlu, E.E., \& Gabbriel,U.U. 2011. Effect of sublethal concentrations of Lepidagathis alopecuroides aqueous extract on the efficiency of spermatogenesis in gravid broodstock Fresh water African catfish Clarias gariepinus. Research Journal of Environmental Toxicology, 5 (1), 27-38

[12] Yasser A. Ahmed, Nada A. Abdel Samei and Ahmed Z. Zayed, 2013. Morphological and Histomorphological Structure of Testes of the Catfish "Clarias Gariepinus" From Egypt. Pakistan Journal of Biological Sciences, 16: 624-629.

[13] Matta SLP, Vilela DAR, Godinho HP, Franc, a LR. 2006. The goitrogen 6-npropyl-2-thiouracil (PTU) given during testis development increases cells transplantation in fish: the Nile-tilapia model. Anim Reprod 3:146-159.

[14] Batlouni,S.R.,Nóbrega,R.H.França,L.R.,2009.Cell junctions in fish seminiferous epithelium.Fish Physiol. Biochem.35,207-217.

[15] Nkanga, E.E.1997. Kinetics of spermatogenesis and germ cell Degeneration of the domestic fowl (Gallus domesticus). Niger Delta Biologia, 2 (1a), 19-27.

[16]. No brega RH, Batlouni SR, Franc s a LR. 2009. An overview of functional and stereological evaluation of spermatogenesis and germ cell transplantation in fish. Fish Physiol Biochem 35:197-206.

[17] Hess,R.A.,França,L.R 2007.Spermatogenesis and cycle of the seminiferous epitheliuIn:Cheng,C.Y.(Ed.),Molecular mechanisms in spermatogenesis. Landes Bioscience pp.1-15.

[18] Orlu, E.E., \& Egbunike, G.N. 2009.Daily Sperm production of the Domestic fowl (Gallus domesticus) determined by quantitative Testicular histology and homogenate methods. .Pakistan Journal of Biological Sciences, 12(20), 1359-1364

[19] Almeida,F.F.L.,KristoffersenC.,Taranger,G.L.,Schulz,R.W.,2008.Spermatogenesis in Atlantic cod (Gadus morhua): a novel model of cystic germ cell development. Biol.Reprod.78,27-34.

[20] Vilela DAR, Silva SGB, Peixoto MTD, Godinho HP, Franc, a LR. 2003.Spermatogenesis in teleost: insights from the Nile tilapia (Oreochromis niloticus) model. Fish Physiol Biochem 28:187-190.

[21] García-López, Á., Martínez-Rodríguez, G.,Sarasquete, C.,2005. Male reproductive system in Senegalese sole Solea senegalensis (Kaup):anatomy, histology and histochemistry.Histol. Histopathol. 20, 1179-1189.

[22] Weltzien FA, Taranger GL, Karlsen $\varnothing$, Norberg B. 2002. Spermatogenesis and related plasma androgen levels in Atlantic halibut (Hippoglossus hippoglossus L.). Comp Biochem Physiol A Mol. Integr. Physiol.132(3),567-75.

[23] Lopes, D.C.J.R., N. Bazzoli, M.F.G. Brito and T.A. Maria, 2004. Male reproductive system in the South American catfish Conorhynchus conirostris. J. Fish Biol., 64: 1419-1424.

[24] Orlu,E.E.and Ogbalu,O.K.2013. Evaluation of the effect of water soluble fraction (wsf) of Bonny light crude oil and Sublethal concentrations of Lepidagathis alopecuroides (Vahl) on reproduction in Clarias gariepinus (Burchell 1822.International Journal of Animal and Veterinary Advances 5(6),240-244 